\title{
Key Energy and Technological Aspects of Three Innovative Concepts of District Energy Networks
}

\author{
Samuel Henchoz ${ }^{a}$, Patrick Chatelan ${ }^{b}$, François Maréchal ${ }^{c}$ and Daniel Favrat ${ }^{d}$ \\ a Industrial \& Process Energy Systems (ex-LENI), Ecole Polytechnique Fédérale de Lausanne (EPFL), \\ Station 9, CH-1015 Lausanne, Switzerland, samuel.henchoz@epfl.ch, (CA) \\ ${ }^{b}$ Industrial \& Process Energy Systems (ex-LENI), Ecole Polytechnique Fédérale de Lausanne (EPFL), \\ Station 9, CH-1015 Lausanne, Switzerland, patrick.chatelan@epfl.ch \\ ${ }^{c}$ Industrial \& Process Energy Systems (ex-LENI), Ecole Polytechnique Fédérale de Lausanne (EPFL), \\ Station 9, CH-1015 Lausanne, Switzerland, francois.marechal@epfl.ch \\ ${ }^{d}$ Energy Centre, Ecole Polytechnique Fédérale de Lausanne (EPFL), Station 5, CH-1015 Lausanne, \\ Switzerland, daniel.favrat@epfl.ch
}

\begin{abstract}
:
In urban areas, the use of thermal energy services is intensive and relatively heterogeneous by their nature, spatial distribution and temperature level required. In this study three concepts of district energy networks that could provide these services very efficiently to a specific area representative of mid Europe (Geneva) are compared. The focus is on the energy and technological aspects related to each of the proposed networks. These networks are characterized by similar temperature levels; between $9.5^{\circ} \mathrm{C}$ and $18^{\circ} \mathrm{C}$, rely on free cooling for most of the cooling services and use a combination of centralized and decentralized heat pumps to provide the heating services. Two of these concepts exploit the latent heat of evaporation/condensation of $\mathrm{CO}_{2}$ and of the HFO refrigerant R1234yf to store and transfer heat across the network. The third concept is more conventional as it uses the sensible heat of liquid water, however with a small temperature spread $\left(2-8{ }^{\circ} \mathrm{C}\right)$. The three proposed networks allow the waste heat emitted by the users requiring cooling to be collected, transferred and valorised by the users requiring heating, thus reducing the load on the central plant. For the area considered, where the annual heating and cooling demand are 53.1 GWh and $49.4 \mathrm{GWh}$ respectively, the annual final energy (electricity) consumption required to supply the thermal services amounts to $10.87 \mathrm{GWh}$ for the $\mathrm{CO}_{2}$ variant, $10.52 \mathrm{GWh}$ for the water variant and $9.60 \mathrm{GWh}$ for the R1234yf variant.
\end{abstract}

\section{Keywords:}

District heating, District cooling, Refrigerant, Urban energy systems, Heat Pump.

\section{Introduction}

Urban areas represent an ever increasing challenge in term of energy use and environmental impact associated with it. According to the World Bank [1], the share of the world population living in urban areas rose steadily from $34 \%$ to $53 \%$ over the period 1961-2013, and projections from the United Nation expect this number to reach $66 \%$ by 2050. In Switzerland the current figure is $73 \%$ which is on parity with the value in Europe. According to URBACT [2] the building sector in the European Union accounts for $40 \%$ of the final energy consumption and $36 \%$ of the emissions of greenhouse gases. It also considers that energy efficiency in buildings located in urban areas represents one of the greatest potential to reduce greenhouse gas emissions and the impact of the european society on the climate. According to the Swiss Federal Office for Energy [3], the final energy consumption associated with thermal energy services in the sectors of households, services, industries are $87.6 \%, 71.5 \%$ and $68 \%$ respectively. Therefore, in order to realize the potential of energy savings in urban areas, it appears crucial to develop efficient energy conversion technologies dedicated to thermal services.

The present study compares three concepts of district energy networks, relying on heat pumps both centralized and decentralized as introduced in particular by [4], for an area in a city centre representative of mid Europe (Geneva) on an energy basis and also from a technical point of view. 
The goal is to provide a valuable insight on the potential of such two pipes networks that can inherently exploit the synergies that exist between the various users.

\section{Case study}

The following study is based on the implementation of a heating and cooling district network in the area of "Rues Basses" in Geneva described in [5]. This area is divided in 32 subareas composed of different types of building, each of them being characterized by the five following services:

- Space heating

- Air conditioning

- Hot water preparation

- Refrigeration (for commercial use)

- Cooling of data centres

Yearly energy requirements of these services are based on the Swiss Standards [6] and the literature [7]. Their values are given in Table 1 for the six types of building considered. The computation of the space heating and air conditioning requirements is based on the definition of the building loss coefficient and the use of daily heating and cooling degree-days as explained in [5]. Figure 1 shows the energy demand expressed in daily values of the entire area in 2012. 53.1GWh have to be provided annually by the network to satisfy space heating and hot water preparation requirements. The heat removed by the network to satisfy cooling services amounts to $49.4 \mathrm{GWh}$. By connecting heating and cooling users together, the network allows thermal exchanges between them.

Table 1. Yearly energy requirements per square meter for the different services

\begin{tabular}{llllllll}
\hline & Units & Shops & Restaurants & $\begin{array}{l}\text { Offices } \\
\text { individual }\end{array}$ & $\begin{array}{l}\text { Offices } \\
\text { open S. }\end{array}$ & $\begin{array}{l}\text { Residential } \\
>1990\end{array}$ & $\begin{array}{l}\text { Residential } \\
<1990\end{array}$ \\
\hline Space heating & {$\left[\mathrm{kWh} \mathrm{m}^{-2} \mathrm{yr}^{-1}\right]$} & 124.6 & 66 & 55 & 55 & 37.5 & 70.6 \\
Air conditioning & {$\left[\mathrm{kWh} \mathrm{m}^{-2} \mathrm{yr}^{-1}\right]$} & 70 & - & 72 & 45 & - & - \\
Hot water prep. & {$\left[\mathrm{kWh} \mathrm{m} \mathrm{m}^{-2} \mathrm{yr}^{-1}\right]$} & 7.4 & 66 & - & - & 12.5 & 21.4 \\
Refrigeration & {$\left[\mathrm{kWh} \mathrm{m}^{-2} \mathrm{yr}^{-1}\right]$} & 30 & 10 & - & - & - & - \\
Data centre cooling & {$\left[\mathrm{kWh} \mathrm{m}^{-2} \mathrm{yr}^{-1}\right]$} & - & - & 8 & 45 & - & - \\
\hline
\end{tabular}

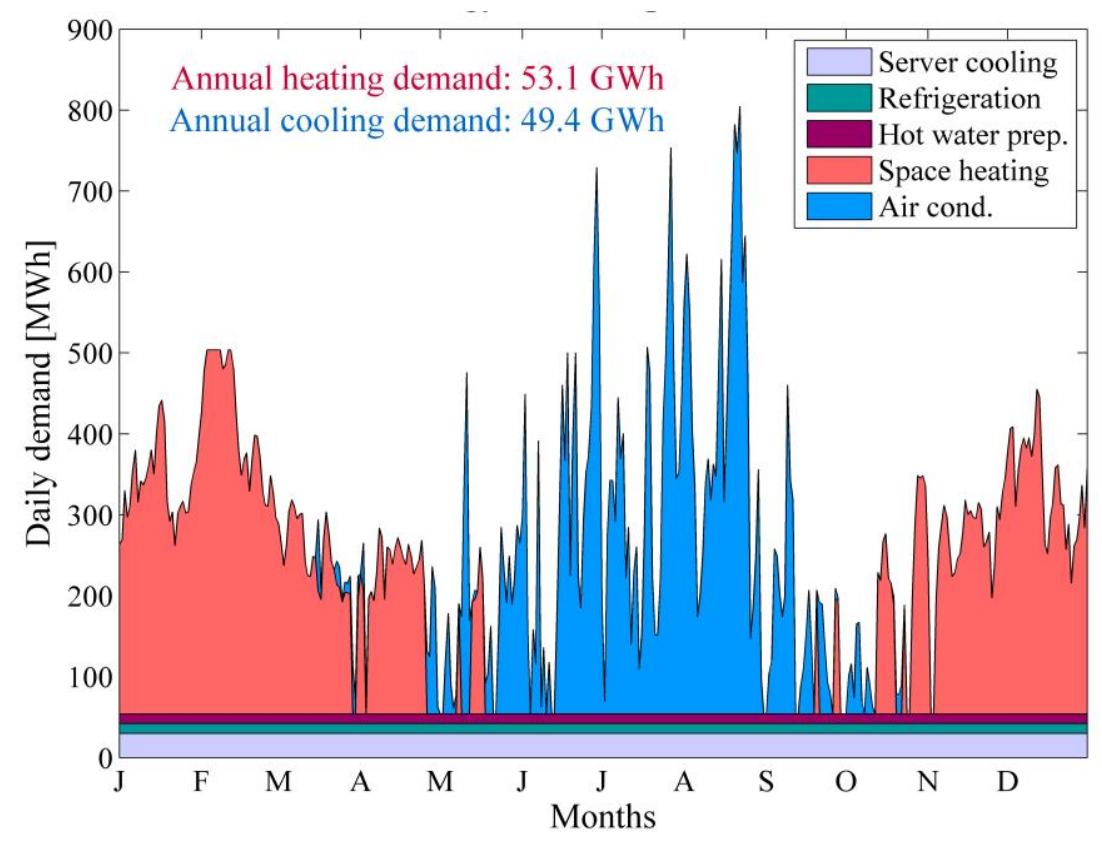

Fig. 1. Energy demand for the area studied, over the year 2012 and per type of energy service. 


\section{Energy conversion technology}

\section{1. $\mathrm{CO}_{2}$ network}

The concept of the $\mathrm{CO}_{2}$ network studied here is the one described by Weber and Favrat in [8,9]. Heat transfer between the network and users is achieved using the latent heat of carbon dioxide near the saturation state in a vapour and a liquid line. The choice of $\mathrm{CO}_{2}$ as a heat transfer fluid comes from the fact that it is the only non-toxic, non-flammable, natural refrigerant available in the desired range of temperatures for the network. The lowest pressure and its corresponding saturation temperature is chosen such as to enable the use of free-cooling for air conditioning and the cooling of data centres, which constraints the maximal temperature of the network at $12.5^{\circ} \mathrm{C}$ during the air conditioning season $\left(\mathrm{T}_{\mathrm{a}}>18^{\circ} \mathrm{C}\right)$ and $22.5^{\circ} \mathrm{C}$ the rest of the time. The saturation pressure corresponding to these temperatures is respectively 47 and 61 bar, representing a challenge from the point of view of the acceptability of the technology by the authorities and the public. It also corresponds to high reduced pressures of 0.637 and 0.827 respectively, which translate into relatively high densities for both the vapour and liquid phases. Thanks to to the use of the latent heat of evaporation of $190 \mathrm{~kJ} \mathrm{~kg}^{-1}$ and $135 \mathrm{~kJ} \mathrm{~kg}^{-1}$ respectively, it results in networks requiring pipelines that have a small cross section.

To allow the fluid to flow directly through the evaporators without any compressor/pump the pressure of the liquid line is set 1 bar above the saturation pressure of the vapour line. The refrigeration requirements are satisfied by local vapour compression chillers in which the $\mathrm{CO}_{2}$ from the liquid line is expanded through an expansion valve, evaporated and recompressed in the vapour line (Fig. 2 left). The installed power of the decentralized cooling equipments is based on a design atmospheric temperature of $30^{\circ} \mathrm{C}$ [5]. The installed heat exchanger area is computed based on the LMTD in the exchanger and supposing a heat transfer coefficient of $2500 \mathrm{Wm}^{-2} \mathrm{~K}^{-1}$. The electrical consumption of the refrigeration systems is approximated using ideal Carnot cycles multiplied by a constant exergy efficiency as explained in [5]. Space heating and hot water preparation are based on the heat provided by the condensation of the $\mathrm{CO}_{2}$ vapour. In each subarea, intermediate heat pumps are used in order to transfer this heat from the network to the users and to adapt its temperature to the desired level. The use of intermediate heat pumps is the consequence of the low critical temperature of $\mathrm{CO}_{2}\left(31.0^{\circ} \mathrm{C}\right)$ that prevents efficient heat pump open cycles to be used for space heating applications. Considering the trend of restricting the use of HFC refrigerants in Switzerland and in a foreseeable future in the rest of the world, [10, 11], the HFO refrigerant R1234yf is considered to be the working fluid of these intermediate heat pumps.
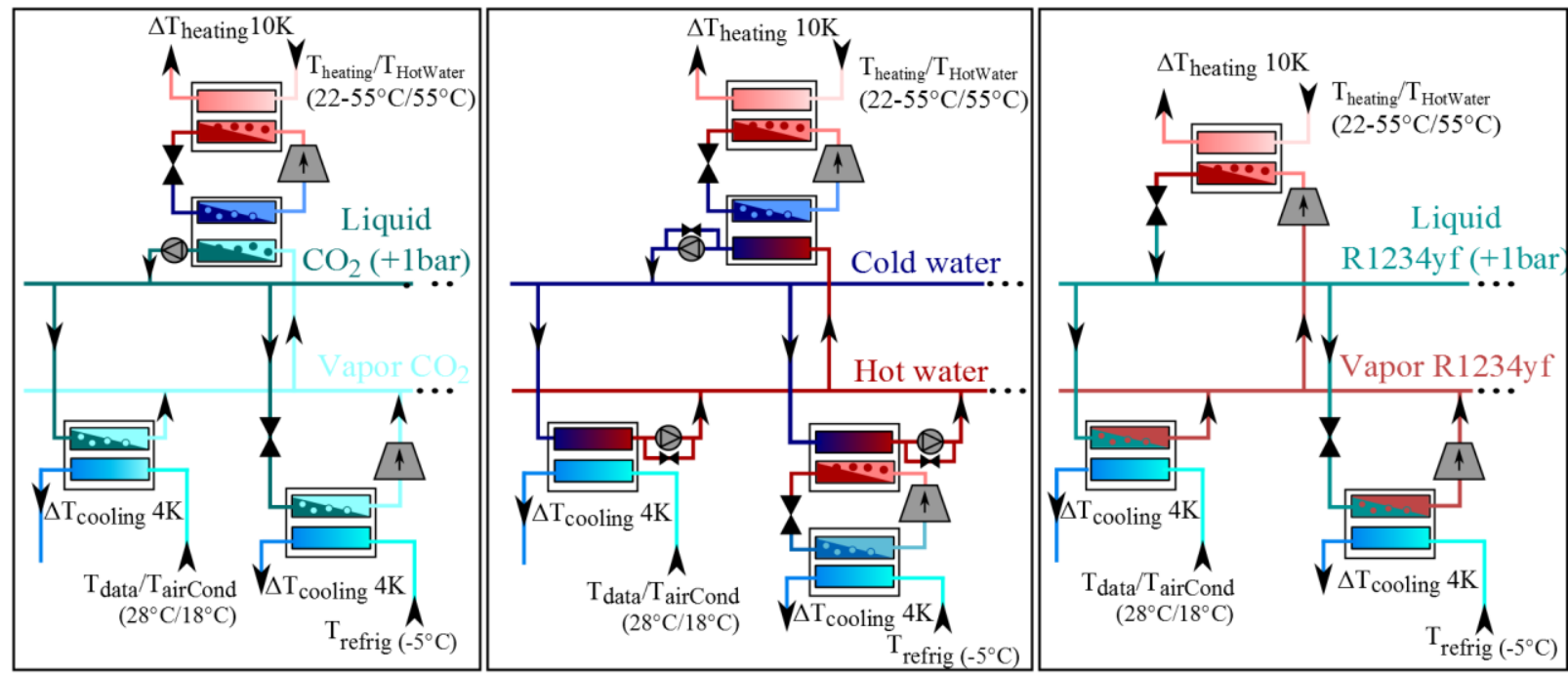

Fig. 2. Schematic representation of the decentralized heating and cooling equipments considered. (Left) CO2 network, (centre) water network, (right) R1234yf network 
The design temperature of the heating equipment is based on an atmospheric temperature of $-7^{\circ} \mathrm{C}$. The heat pump cycle calculations are described in section 4 and are used to define the compressor work and the necessary installed power. As explained in [5], the installed electric power per heat pump is limited to $67 \mathrm{~kW}$. Depending on the subarea requirements, multiple heat pumps have to be installed.

The electrical consumption of the refrigeration chillers and heat pumps depend on the setpoint temperatures of the corresponding services given in Fig.2. For space heating, a heating curve defined in [5] is used. It relates the hydronic loop supply temperature to the daily mean atmospheric temperature.

Since cooling and heating requirements are not balanced throughout the year, a central plant is used to supply or remove heat from the network. It was supposed that the necessary heat can be taken or released in a water source at a constant temperature $\left(7.5^{\circ} \mathrm{C}\right)$ [12]. Considering a pinch temperature of $1.5 \mathrm{~K}\left(\Delta \mathrm{T}_{\operatorname{minRR}}\right)$ and a temperature difference of $0.5^{\circ} \mathrm{C}$ between the inlet and the outlet of the water source, the minimal network temperature is limited to $9.5^{\circ} \mathrm{C}$. A more detailed description of the central plant operation is given in [5]. Based on the energy requirements of the 32 subareas and their distribution along the network, the $\mathrm{CO}_{2}$ massflow in the lines can be computed as presented in [5]. The massflow needed by a subarea takes into account internal exchanges. For example, in winter, the vapour rejected by the refrigeration systems is directly used by the heat pumps of the subarea, which reduces the massflow of vapour that has to be provided by the network itself. According to [13], the liquid pipe diameters have to be chosen so that the liquid velocity does not exceed a certain limit above which cavitation can occur. This limit is $2.1 \mathrm{~ms}^{-1}$ for $200 \mathrm{~mm}$ diameters, $2.5 \mathrm{~ms}^{-1}$ for $300 \mathrm{~mm}$ diameters and $3 \mathrm{~ms}^{-1}$ for diameters above $500 \mathrm{~mm}$. For the case studied in this paper, a liquid $\mathrm{CO}_{2}$ line diameter of $270 \mathrm{~mm}$ is sufficient to respect this velocity constraint. Note that the maximum massflow is defined by the air conditioning peak of demand in summer. (See Fig. 1.)

Pressure drops along the vapour and liquid lines are computed using Churchill's correlation. High pressure drops can cause temperature variations along the lines and decrease the decentralized heat pumps efficiency. It can also promote the emergence of two-phase flows that have to be avoided for operational reasons. In order to limit these two effects, pressure drops are limited at 1 bar. Booster compressors and pumps are therefore installed along the lines to fulfil this pressure drop constraint. The liquid pipe diameters given by the velocity constraint allow a single pump to be used on the liquid $\mathrm{CO}_{2}$ line. A vapour pipe diameter of $330 \mathrm{~mm}$ is necessary to require only one single booster compressor along the line. This was found to be the optimum economic trade-off between investment in piping and machinery vs. operating costs [5].

\subsection{Water network}

Instead of using the latent heat, the sensible heat of liquid water can be used to satisfy the heating and cooling requirements. This type of network uses similar equipment (Fig. 2 middle) as the $\mathrm{CO}_{2}$ network, but unlike the latter it can be operated at a much lower pressure of a few bar only. A minimal temperature difference of $2^{\circ} \mathrm{C}$ between the hot and the cold water lines was set. As for the $\mathrm{CO}_{2}$ network, air conditioning and the cooling of data centres are also satisfied using free cooling. The hot and cold water temperatures are therefore limited to respectively $16^{\circ} \mathrm{C}$ and $12^{\circ} \mathrm{C}$ when air conditioning is needed and to $26^{\circ} \mathrm{C}$ and $22^{\circ} \mathrm{C}$ the rest of the time. Unlike $\mathrm{CO}_{2}$, water cannot be directly used in refrigeration systems. An additional heat exchanger has to be installed decreasing the system efficiency. A modification must also be done at the central plant in heat pumping mode (Fig. 3). The renewable heat is used to evaporate an intermediate refrigerant (R1234yf) that is then compressed and condensed to transfer the heat to the water network. The operating principle of the central plant removing heat from the network ("summer" mode) is simply done using a heat exchanger like in the case of the $\mathrm{CO}_{2}$ network. Instead of having only a single $\mathrm{CO}_{2}$-water heat exchanger that can be used as an evaporator ("winter" mode) or as a condenser ("summer" mode), the central plant of the water network needs to be equipped with three different heat exchangers. 


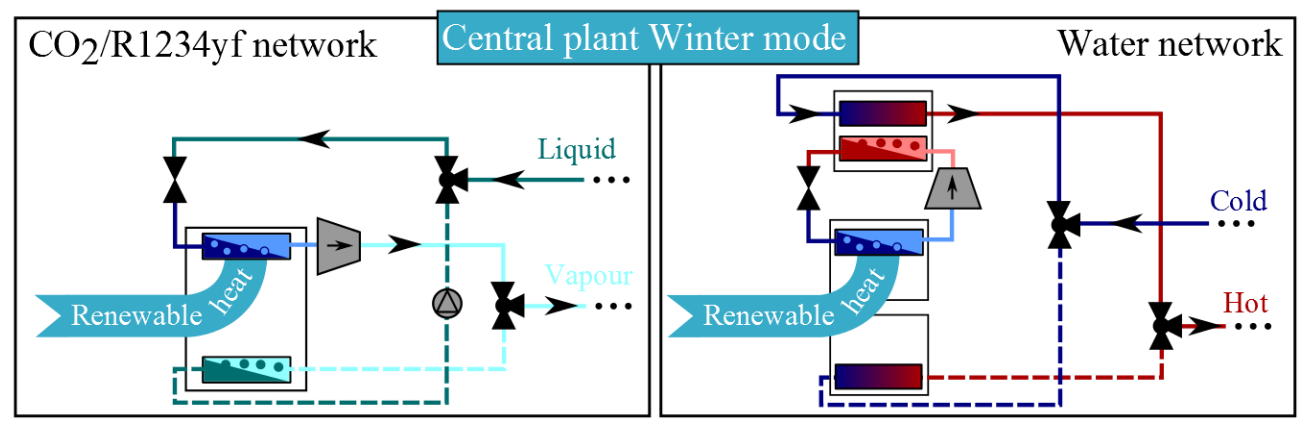

Fig. 3. Schematic representation of the layout of the central plant. (Left) $\mathrm{CO}_{2}$ resp. $\mathrm{R} 1234 \mathrm{yf}$ networks, (right) water network. Both represent the operation in winter mode (heat pumping.)

The water massflow calculations are similar to the one presented for the $\mathrm{CO}_{2}$ network in [5] with the latent heat being replaced by the enthalpy difference between hot and cold water. The pipe diameters are defined regarding the limit indicated by [13]. It is directly linked to the water temperature difference between hot and cold water. A temperature difference of $2^{\circ} \mathrm{C}$ corresponds to a diameter of $1085 \mathrm{~mm}$. Knowing the pipe diameters and the necessary water massflows of the 32 subareas the pressure drop evolution along the lines is computed also using Churchill's correlation. Depending on its heating and cooling load and its location along the network, each subarea sees a different pressure difference between the hot water line and the cold water line $\left(\Delta \mathrm{P}_{\mathrm{h}-\mathrm{c}}\right)$. Therefore each subarea is equipped with a water pump and a valve to control the flowrate depending on the sign of $\Delta \mathrm{P}_{\mathrm{h}-\mathrm{c}}$. Based on data from a manufacturer [14], the electric efficiencies of the water pumps are evaluated as follows:

$\eta_{\text {pump }}=-1.63\left(\frac{\dot{m}}{\dot{m}_{\text {sizing }}}\right)^{2}+1.94\left(\frac{\dot{m}}{\dot{m}_{\text {sizing }}}\right)+0.03$

Unlike with the $\mathrm{CO}_{2}$ network no booster pumps are installed along the lines since each subarea has its own pump. Considering a constant water density, the daily electric consumption of a water pump is given by:

$$
E_{\text {pump }}=\frac{24 \Delta P_{h-c} \dot{m}}{\rho_{\text {water }} \eta_{\text {pump }}}[W h]
$$

\subsection{R1234yf network}

The use of refrigerant $\mathrm{R} 1234 \mathrm{yf}$ instead of $\mathrm{CO}_{2}$ is another way to reduce the operating pressure of the network while keeping the advantage of playing with the latent heat. For saturation temperatures varying between $12.5^{\circ} \mathrm{C}$ and $22.5^{\circ} \mathrm{C}$, the corresponding pressures vary between 4.7 and $6.4 \mathrm{bar}$ which is typical of natural gas urban networks. The temperature of $\mathrm{R} 1234 \mathrm{yf}$ critical point is $94.7^{\circ} \mathrm{C}$ instead of $31.0^{\circ} \mathrm{C}$ for $\mathrm{CO}_{2}$. This allows the use of open-cycle heat pumps (Fig. 2 right) taking the R1234yf directly out of the saturated vapour line, compressing it, condensing it to provide the required heating service, and expanding it through a valve to the liquid line of the network. Note that the process is very similar to the one used for refrigeration in this network and in the $\mathrm{CO}_{2}$ variant. Obviously, the efficiency of these heat pumps is increased by the suppression of the heat transfer losses in an evaporator.

The network temperature is limited by the same constraints than the ones expressed for the $\mathrm{CO}_{2}$. As for liquid $\mathrm{CO}_{2}$ pipes and water pipes, the minimal diameter of the liquid $\mathrm{R} 1234 \mathrm{yf}$ line is constrained by the limit given in [13]. As a consequence the minimal liquid R1234yf pipe diameters are 265 mm.

A pressure drop of 1 bar along the $\mathrm{CO}_{2}$ network corresponds approximately to a drop in saturation temperature of $0.9^{\circ} \mathrm{C}$. The same drop in temperature is obtained for the R1234yf with a pressure 
drop of 0.15 bar only. Each time such a pressure drop is reached along the liquid or the vapour line, a booster pump or compressor has to be installed. For a liquid R1234yf line diameter of $270 \mathrm{~mm}$, pumps have to be installed at four different locations along the line. To require only one single booster compressor along the vapour line, the diameter of the latter would have to be $710 \mathrm{~mm}$.

\section{Electrical consumption of the networks}

\subsection{Sensitivity of the global electrical consumption}

The pipe diameters of the different networks are fixed by applying the velocity constraint on liquids, by considering that compressors are installed at only one location along the vapour lines and by limiting the pressure drops to 1 bar for $\mathrm{CO}_{2}$ and 0.15 bar for $\mathrm{R} 1234 \mathrm{yf}$. The values are summarized in Table 2. Hence, the energy consumptions (electricity) of the different networks are only dependant on the temperatures of the network. The central plant and the decentralized heat pumps represent the most important electrical consumptions. During the air conditioning season $\left(\mathrm{T}_{\mathrm{a}}>18^{\circ} \mathrm{C}\right)$, the temperature of the network temperature has only a very limited impact on the overall electricity consumption since it only affects the production of domestic hot water and the refrigeration. Figure 4 shows the sensitivity of the annual electrical consumption of the three networks to their respective temperature in "winter" (no air conditioning demand). Table 2 summarizes the results for the temperatures of the networks that minimize the global electrical consumption. Note that the temperature difference between the hot and cold lines in the water network option is assumed constant throughout the year.

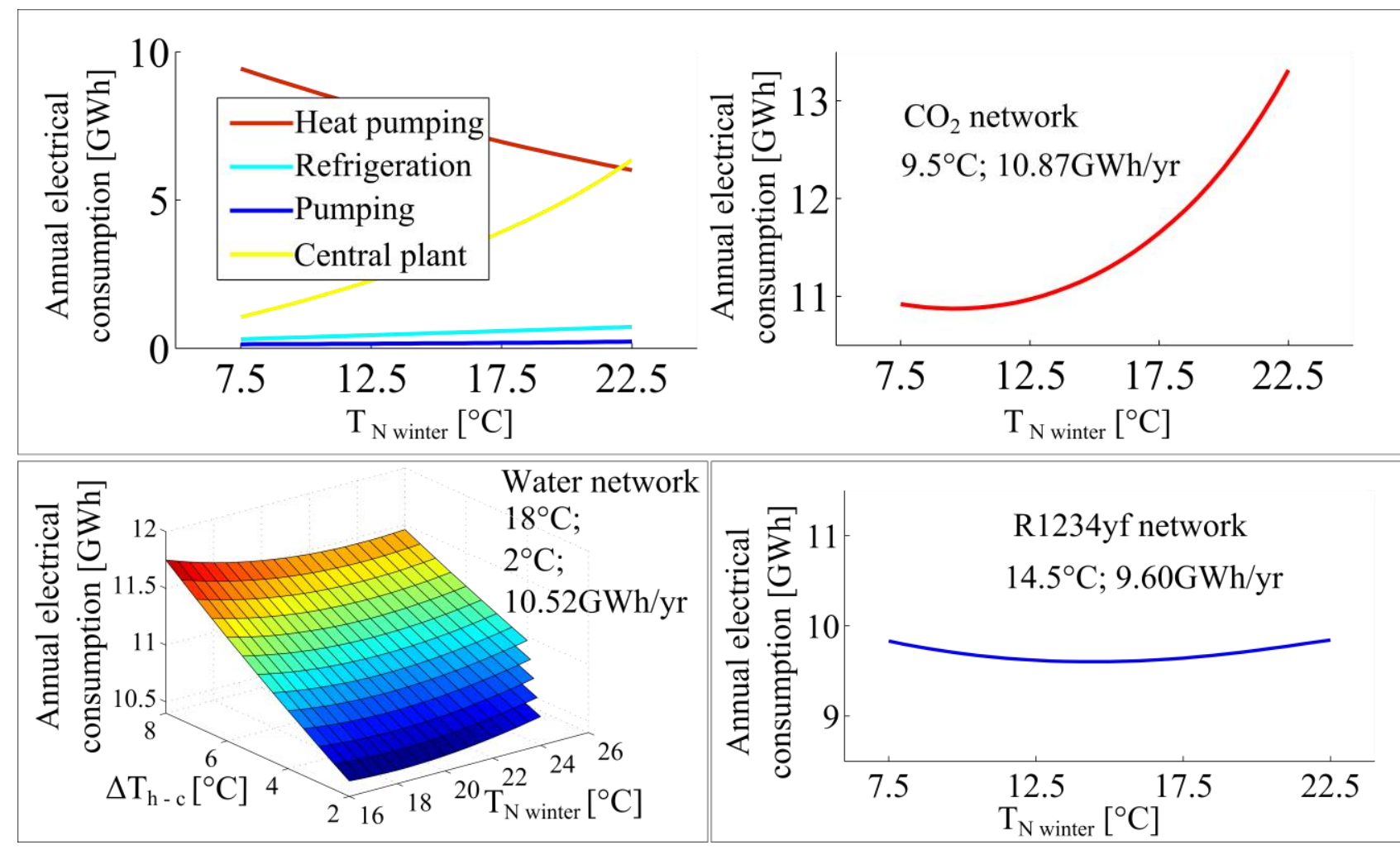

Fig. 4. Sensitivity analysis of the network annual electrical consumption to the network temperature in winter (and temperature difference for the water network). (Top) $\mathrm{CO}_{2}$ network, (Bottom-left) water network, (Bottom-right) R1234yf network.

As expected, when the winter temperature of the networks is increased, the electrical demand of the decentralized heat pumps decreases while the one of the central plant increases. However, the winter temperature that minimizes the overall electrical demand differs for each variant of network, according to the relative importance of the exergy losses in either the central plant or the decentralized heat pumps. More specifically, the exergy efficiency of the central plant in the $\mathrm{CO}_{2}$ network is lower than that in the R1234yf counterpart, which explains the lower optimal winter 
temperature for the $\mathrm{CO}_{2}$ variant. For the water network, the temperature difference between the hot and cold line forces down the evaporation temperature in the decentralized heat pumps causing some exergy losses. This effect shifts slightly the balance between the electricity consumption of the decentralized heat pumps and the central plant towards a higher optimal winter. Of the three proposed network, R1234yf exhibits the best energy performance, mostly because of the open cycle heat pumps (both centralized and decentralized) that eliminate the exergy losses in the evaporators of the decentralized heat pumps as well as in the condenser of the centralized heat pump.

At equal temperature the saturated vapour density of the $\mathrm{R} 1234 \mathrm{yf}\left(24 \mathrm{kgm}^{-3}\right.$ at $\left.9.5^{\circ} \mathrm{C}\right)$ is much lower than the one of $\mathrm{CO}_{2}\left(133 \mathrm{kgm}^{-3}\right)$ which leads to larger vapour line diameters. A reduction of the R1234yf vapour line diameter to the $\mathrm{CO}_{2}$ network's value $(330 \mathrm{~mm})$ would require booster compressors to be installed in eight locations along the line instead of one. The electrical consumption due to pumping (booster pumps and compressors) would increase to $2.28 \mathrm{GWh} / \mathrm{yr}$, which is around fifty times the consumption obtained for a diameter of $710 \mathrm{~mm}$.

Table 2. Characteristics minimizing the overall electricity consumption of the three types of network.

\begin{tabular}{lllll}
\hline & Units & $\mathrm{CO}_{2}$ & Water & R1234yf \\
\hline $\mathrm{T}_{\mathrm{N} \text { winter }}$ & {$\left[{ }^{\circ} \mathrm{C}\right]$} & 9.5 & $18-16$ & 14.5 \\
$\mathrm{~T}_{\mathrm{N} \text { summer }}$ & {$\left[{ }^{\circ} \mathrm{C}\right]$} & 9.5 & $14-12$ & 9.5 \\
\hline $\mathrm{D}_{\text {vap }}$ & {$[\mathrm{mm}]$} & 330 & - & 710 \\
$\mathrm{D}_{\text {liq }}$ & {$[\mathrm{mm}]$} & 270 & 1085 & 265 \\
\hline Heat pumping & {$[\mathrm{GWh} / \mathrm{yr}]$} & 8.87 & 6.94 & 6.96 \\
Refrigeration & {$[\mathrm{GWh} / \mathrm{yr}]$} & 0.36 & 0.68 & 0.50 \\
Pumping & {$[\mathrm{GWh} / \mathrm{yr}]$} & 0.14 & 0.05 & 0.04 \\
Central plant & {$[\mathrm{GWh} / \mathrm{yr}]$} & 1.5 & 2.84 & 2.10 \\
Total & {$[\mathbf{G W h} / \mathbf{y r}]$} & $\mathbf{1 0 . 8 7}$ & $\mathbf{1 0 . 5 2}$ & $\mathbf{9 . 6 0}$ \\
\hline $\mathrm{COP}_{\mathrm{H}+\mathrm{C}}$ & {[]} & 9.4 & 9.7 & 10.7 \\
\hline
\end{tabular}

The network efficiency is evaluated by the $\mathrm{COP}_{\mathrm{H}+\mathrm{C}}$ of the network that is obtained by dividing the sum of the annual heating and cooling requirements $(102.5 \mathrm{GWh})$ by the network annual electrical consumption as defined in equation (3).

$$
C O P_{H+C}=\frac{\int\left|\dot{Q}_{H}\right|+\left|\dot{Q}_{H W}\right|+\left|\dot{Q}_{A C}\right|+\left|\dot{Q}_{\text {data }}\right|+\left|\dot{Q}_{\text {refr }}\right| \cdot d t}{\int \dot{E} \cdot d t}
$$

Fig. 5 provides the T-s diagrams of the cycles in space heating heat pumps for the winter design conditions $\left(\mathrm{Ta}=-7^{\circ} \mathrm{C}\right)$. The assumptions used in computing these cycles are similar to those described in [5].

The values of the COP of the centralized and decentralized heat pumps are provided in Table 3 for each variant of network. Note that the values for decentralized heat pumps are those at the winter design conditions.

Table 3. Coefficient of performance of the decentralized heat pumps used for space heating (at winter design conditions: $\mathrm{Ta}=-7^{\circ} \mathrm{C}$ ) and of the heat pump at the central plant.

\begin{tabular}{lcccc}
\hline & Units & $\mathrm{CO}_{2}$ network & Water network & R1234yf network \\
\hline $\mathrm{COP}_{\mathrm{H}}$ & {[]} & 3.9 & 5.0 & 5.0 \\
$\mathrm{COP}_{\text {central }}$ & {[]} & 22.6 & 12.6 & 17.0 \\
\hline
\end{tabular}




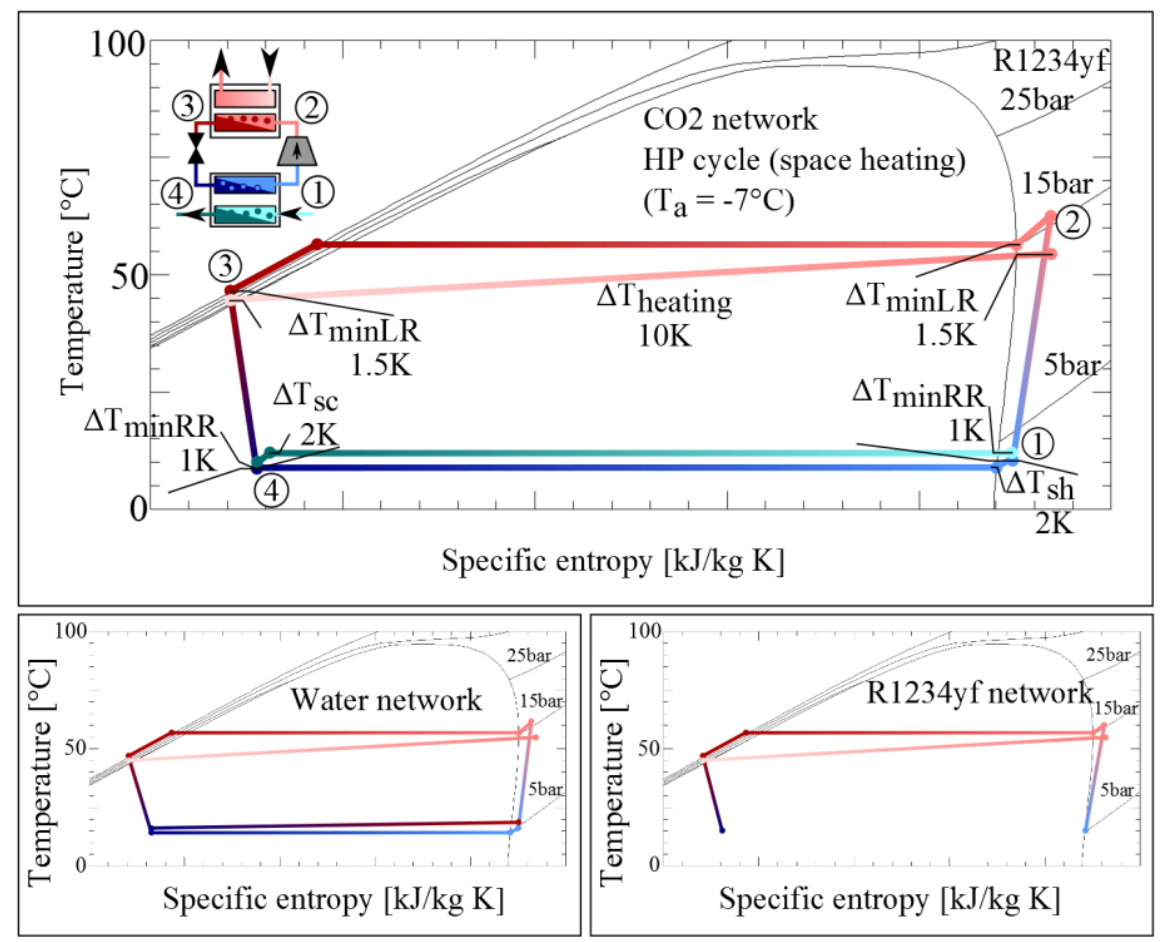

Fig. 5. T-s diagrams of the space heating heat pump cycles for the $\mathrm{CO}_{2}$ (top), water (bottom left) and R1234yf (bottom right) network variant.

\subsection{Impact of the heating and cooling requirements on the electrical consumption}

A sensitivity analysis was carried out. It aimed at assessing whether the ranking (with respect the electricity consumption) between the three proposed networks depends on the heating/cooling requirements. The total heating/cooling requirements were varied between $50 \%$ and $150 \%$ of their actual value. The relative ratio between space heating and the production of domestic hot water was kept constant. Similarly, the ratio between air conditioning, refrigeration and cooling of data centres was also kept constant. The results are shown in Fig. 6.

It appears that the ranks are not affected by changes in the heating requirement (Fig. 6 top-left) or in the cooling requirements (Fig. 6 bottom-left), meaning that the energy efficiency of each network is relatively site independent.

Unlike the energy efficiency, the optimal temperature of the networks in winter depends on the respective amounts of heating and cooling required. Interestingly, for increased heating requirements, the winter optimal temperature decreases (Fig. 6 top-right), while for increased cooling requirements the optimal winter temperature increases (Fig. 6 bottom-right). Though counter-intuitive, it is explained by the fact that an increased share of heating requirements leads to a larger amount of heat to be provided by the centralized heat pump, itself leading to a higher relative exergy loss of the central plant over decentralized heat pumps. It results in a shift of the optimal temperature towards a lower value. Reversely when the share of cooling increases, the load on the centralized heat pump is reduced, leading to a reduced relative exergy loss of the central plant that shifts the optimal temperature towards a higher value. 


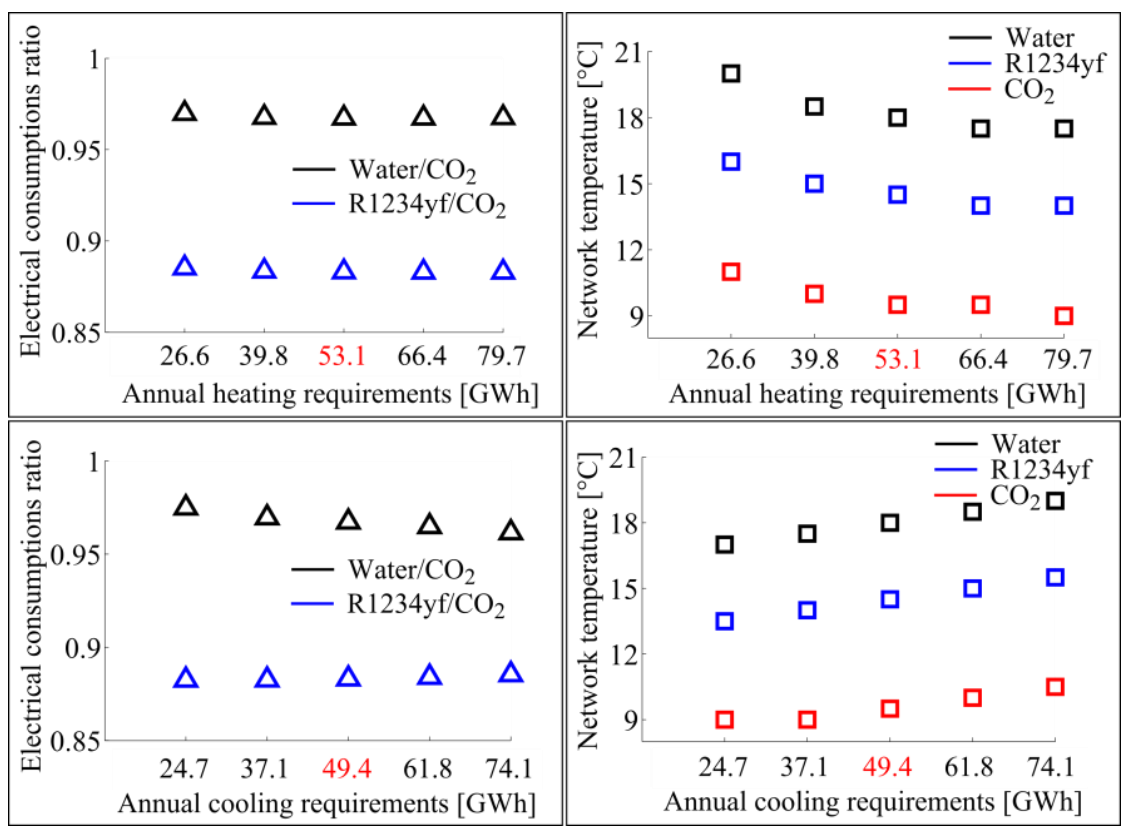

Fig. 6. Sensitivity of the annual electrical consumptions and optimal network temperature to changes in heating requirements (top) and cooling requirements (bottom) Note: The base case values are in red.

\section{Additional considerations on compactness}

It is a known fact that district heating and cooling should preferably be placed in areas with high energy density. However, as high energy density is generally correlated with a high population density, many reasons can impede the realization of a district heating/cooling network in a given area, such as:

- A congested underground, due to the presence of other infrastructures such as fresh water pipes, sewers, natural gas pipelines, underground power or telecommunication lines.

- The presence in the area of important public transportation facilities that would be too difficult/costly to re-route or interrupt during the construction of the network.

- A re-routing of the road traffic during the construction that would be too difficult.

All these constraints could be relaxed, if a more compact form of network could be built. Smaller cross sections would give more freedom to lay the network among the other underground infrastructures. It would also reduce the footprint and the time duration of the construction, which result in lower perturbations of the road and public transportation, reduced costs and potentially a better acceptance.

Among the three proposed networks, the water variant is the least favourable from the point of view of the compactness. The primary reason is the low energy density that results from the small enthalpy difference between the two lines. The resulting large massflow of water in the network combined with the restriction on the maximum water velocity leads to large pipe diameters. The second reason is the necessity to bury the pipe deep enough to prevent the water inside them from freezing, should a section of the network be disabled for long enough in winter time. Note that for all networks the low temperature differential between the fluid and the soil allows for smaller amounts of insulation to be used in comparison with more conventional networks. Typically for Geneva, the minimum freeze safe depth is $90 \mathrm{~cm}$ above the top of the pipes. For pipes directly buried in the ground, as opposed to those put into utility tunnels, a minimum depth is also required to avoid excessive external loading on the pipes for instance due to heavy vehicles. A minimum depth of $1.2 \mathrm{~m}$ above the top of the pipes is required to withstand the mechanical load imposed by bridge-class SLW60 vehicles for DN600 - DN1000 pre-insulated pipes [17]. Hence, in the present case, the depth of the trench is constrained by the necessity to withstand the traffic load. 
However the compactness of the proposed cold water network could be improved by increasing the temperature difference between the two lines. Fig. 4 clearly shows the higher electricity consumption that would result. In the current study, the choice of using free cooling for the cooling of data centres and the air conditioning imposes a maximum temperature difference that results from the temperature requirement for those services. However, if vapour compression chillers were used instead, the temperature difference could be further increased. Obviously, the penalty on electricity consumption would be even more costly.

The two refrigerant networks are more compact than the water variant as indicated by the diameters of vapour and liquid pipes shown in Table 2. Secondly, the problem of the depth of burial of the refrigerant networks is not constrained by the necessity to avoid freezing but only by the mechanical design load, assumed to be SLW 60 vehicles [17]. The trench cross sections are represented for the three proposed network at scale in Fig. 7, for pipelines directly buried in a road used by heavy vehicles. The shaded area shows the minimum size of the excavation according to [17-18]. The greater compactness of the refrigerant based variants is obvious. In term of excavation work, the volume of material to be processed is $75.4 \%$, respectively $82.2 \%$ lower for the R1234yf and $\mathrm{CO}_{2}$ networks. Such reductions have several advantages, like reduced costs, easier logistic, shorter duration and reduced impact on the direct environment. Compared to the water network, the trench width is also significantly reduced by $65.2 \%$ and $69.6 \%$ for the $\mathrm{R} 1234 \mathrm{yf}$ and $\mathrm{CO}_{2}$ network respectively. Widths of less than 2 metres are especially advantageous in large roads since only one lane will be disabled during the construction, thus preventing a total disruption in the traffic.

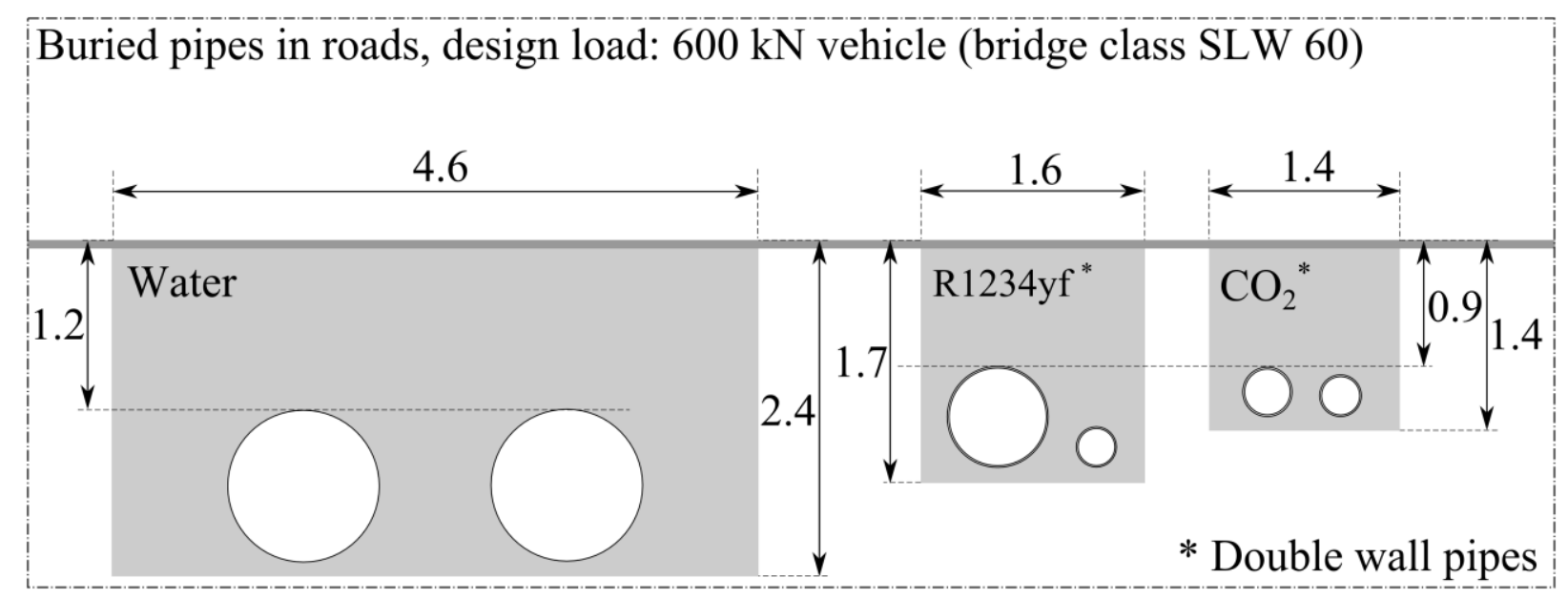

Fig. 7. Representation of the cross sections of the trenches for the three proposed networks. (At scale.)

\section{Conclusion}

Among the three variants of network proposed, the one using R1234yf as a working fluid appears to be the most energy efficient, however not by a very significant margin. Though not discussed in the present study, the evaluation of the investment costs showed that none of the three types is significantly more advantageous than the other two. As a result, one can expect other, more secondary elements, to play the defining role in choosing which of the proposed solutions is the best. Compactness is one of these elements and it is not in favour of the water variant as it requires a significant amount of space due to the low energy density of the heat carrier. On the other hand, one can expect the laying of the pipes to be easier in the case of $\mathrm{a} \mathrm{CO}_{2}$ or a $\mathrm{R} 1234 \mathrm{yf}$ network, since the required size of the pipes and the necessary excavation work are much smaller than for the water counterpart. As a conclusion, in spite of relatively similar performances to the one of the water network proposed in this study, refrigerant based networks exhibit a significant potential, particularly in urban areas that cannot be reached by the proposed water variant because of a highly congested underground, or because of the difficulties that the construction of a bulkier network might cause to the surrounding urban environment. This potential however will be at reach only 
once safety and regulatory issues linked to the construction and operation of refrigerants based district energy network will have been addressed.

\section{Acknowledgments}

The authors gratefully acknowledge financial support from the Commission for Technology and Innovation - CTI, and the two industrial partners, the engineering firm Amstein \& Walthert Genève SA and the utility company SIG. The authors also acknowledge Mrs Weber and Mr. Rami for their technical support.

\section{Nomenclature}

Acronyms

COP

Coefficient of performance (heat pumps)

\section{Symbols}

$\begin{array}{llll}\dot{E} & \text { Electric power, } \mathrm{W} & P & \text { Pressure } \mathrm{N} \mathrm{m}^{-2} \\ E & \text { Electric work, } \mathrm{Wh} & \dot{Q} & \text { Heat rate, } \mathrm{W} \\ \dot{m} & \text { Massflow, } \mathrm{kg} \mathrm{s}^{-1} & T & \text { Temperature, }{ }^{\circ} \mathrm{C}\end{array}$

\section{Greek symbols}

$\begin{array}{ll}\Delta P & \text { Pressure drop, } \mathrm{Nm}^{-2} \\ \Delta P_{h-c} & \text { Pressure difference betw } \\ \Delta T & \text { Temperature change, } \mathrm{K} \\ \Delta T_{\text {cooling }} & \text { Temperature difference } \\ \Delta T_{\text {heating }} & \text { Temperature difference } \\ \Delta T_{h-c} & \text { Temperature difference } \\ \Delta T_{\min } & \text { Minimum approach te } \\ \Delta T_{s c} & \text { Subcooling, } \mathrm{K} \\ \Delta T_{s h} & \text { Superheat, } \mathrm{K} \\ \eta & \text { Electrical efficiency } \\ \rho & \text { Mass density, } \mathrm{kg} \mathrm{m}^{-3}\end{array}$

\section{Subscripts}

$a$
$A C$
comp
data
$H+C$
liq
$H$

Atmosphere

$L L \quad$ Liquid-liquid (heat exchange)

Air conditioning

Compressor

$L R \quad$ Liquid-refrigerant (heat exchange)

$N \quad$ Network

refr Refrigeration

Data centre cooling

$R R \quad$ Refrigerant-refrigerant (heat exchange)

Heating+cooling (requirements)

vap State in the vapour line

State in the liquid line

Space heating

$H W$ domestic hot water

\section{References}


[1] The World Bank Group [internet]. Washington DC, USA: Website of the World Bank Group, Data on urban population - Available at : 〈http://data.worldbank.org/indicator/SP.URB.TOTL.IN.ZS > [accessed 12.01.15]

[2] Lewis J.O., Ní Hógáin S., Borghi A., Building energy efficiency in European cities - Technical report, URBACT II, European Regional Development Fund, Saint-Denis, France, 2013

[3] Swiss Federal Office for Energy, Analyse des schweizerischen Energieverbrauchs 2000 - 2013 nach Verwendungszwecken, Bern, Switzerland, 2014

[4] Lorentzen G., Heat pumps for district heating applications, in: Proc. of Heat Pump Solving Energy and Environmental Challenges, 3rd IEA-Heat Pump Conference, Tokyo, 1990.

[5] Henchoz S, et al., Performance and profitability perspectives of a $\mathrm{CO} 2$ based district energy network in Geneva's City Centre, Energy (2015), http://dx.doi.org/10.1016/j.energy.2015.03.079

[6] Swiss standard SIA 565 380/1, L'énergie dans le bâtiment, SIA, Zürich (1988), Switzerland

[7] Girardin, L. A GIS-Based Methodology for the Evaluation of Integrated Energy Conversion Systems in Urban Areas, PhD. Thesis, EPFL, 2012

[8] Weber, C. \& Favrat, D. Conventional and advanced $\mathrm{CO}_{2}$ based district energy systems, Energy, 2010, 35, $5070-5081$

[9] Favrat, D. \& Weber C. 2005. CO 2 Based District Energy System. U.S. Patent 2010018668 (A1), filed February 16, 2008, and issued January 28, 2010

[10] Federal Office of Environment Switzerland, Liste des principaux fluides frigorigènes - état juillet 2014, Bern (2014), Switzerland

[11] United Nations Environment Programme, Enabling a global phase-down of hydrofluorocarbons: discussion paper submitted by the European Union, Twenty-Sixth Meeting of the Parties to the Montreal Protocol on Substances that Deplete the Ozone Layer, Paris, France, November 17-21, 2014

[12] Faessler, J.; Haroutunian, A.; Hollmuller P.; Lachal B.; Etude d'opportunité pour le projet GLU/GLA - Technical report, SIG-UNIGE, Geneva, Switzerland, 2011

[13] Recknagel, H.; Sprenger, E.; Hönmann, W. \& Cauchepin, J-L. Le Recknagel : Manuel Pratique Du Génie Climatique, Pyc Edition, Paris, France, 1986

[14] GRUNDFOS Holding A/S [internet]. Bjerringbro, Denmark: Webpage where GRUNDFOS's sizing and selection software can be downloaded - Available at: <http://net.grundfos.com/Appl/WebCAPS/custom?userid=GFD-1> [accessed 09.01.2015]

[15] Navarro-Esbrí, J.; Mendoza-Miranda, J.; Mota-Babiloni, A.; Barragán-Cervera, A. \& Belman-Flores, J. Experimental analysis of R1234yf as a drop-in replacement for R134a in a vapor compression system International Journal of Refrigeration , 2013, 36, 870 - 880

[16] Borel, L. \& Favrat, D. Thermodynamics and Energy Systems Analysis; From Energy to Exergy, Presses Polytechniques et Universitaires Romandes PPUR, Lausanne, Switzerland, 2010

[17] Isoplus Fernwärmetechnik [internet]. Sondershausen, Germany: Webpage where the Isoplus design manual can be downloaded - Available at: <http://www.isopluspipes.com/en/download/design-manual/> [accessed 12.01.2015]

[18] Brugg Rohrsystem AG [internet]. Kleindöttingen, Switzerland: Webpage where the system description of brugg's STAMANT double wall pipes can be downloaded - Available at: 〈http://www.pipesystems.com/domains/pipesystems_com/data/free_docs/indkat_4.pdf > [accessed 12.01.2015] 